\title{
Using Spreadsheets to Assess Learning
}

Judson E. Wagner, Concord High School, Wilmington, DE

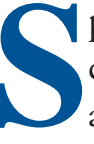
preadsheets can be a powerful tool when it comes to teaching physics. From data analysis and graphing to animated simulations, Excel $^{\odot}$ is a very versatile program for the educator and learner alike. ${ }^{1-4}$ This paper describes and supports another use for Excel through Reflective Formative Assessment Spreadsheets (RFAS). To illustrate the use of RFAS, Fig. 1 shows a released AP Physics 5 question that one student, a group of students, or the entire class may see when they access a prepared RFAS file from a shared drive. Notice that this file has been given a PowerPoint ${ }^{\oplus}$ look by removing scrollbars and gridlines and by using the Full Screen option (Fig. 1, arrow a). Students navigate from one question to the next using the tabs (Fig. 1, arrow b).

Many cells in the spreadsheet are locked to avoid misguided tampering, while a few specific cells are left unlocked for the purpose of allowing students to enter useful information. In this case, students within groups tally and enter votes for a multiple-choice option before discussing the question (Fig. 1, arrow c) and after discussing the question (Fig. 1, arrow d). Then they enter brief explanations as to why some options were chosen and others were not (Fig. 1, arrow e). This is especially useful in identifying latent misconceptions where students can pick the right answer but for unclear or flat-out wrong reasons. Form objects such as the check boxes are used to survey student opinions about the question (Fig. 1, arrow f).

Excel also has password protection, which can allow a teacher to alter both locked and unlocked cells and add or edit text boxes, hyperlinks, images, draw-

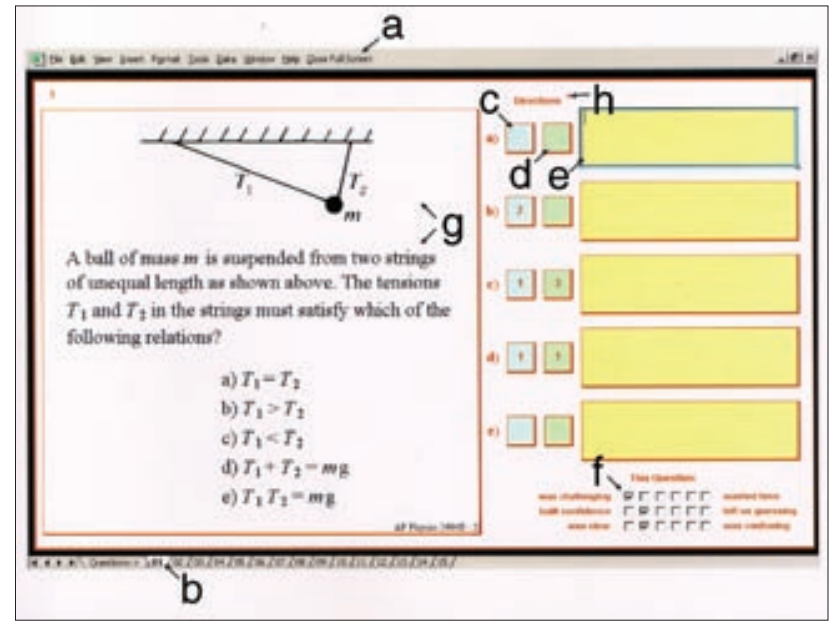

Fig. 1. Screen shot students view when they access a prepared RFAS file from a shared drive.

ing objects (Fig. 1, arrow g), and comments (Fig.1, arrow $\mathrm{h}$ ). There are many other features of Excel that allow it to be fine tuned for ease of use by various learners, but the power comes from the spreadsheet's cell referencing capabilities, which allow the information that was entered by students into the unlocked cells to be collected by a secondary document called Report.xls, also placed on the shared drive.

A sample printout of the report on the question in Fig. 1 is given in the Ref. 6. Automatically and instantaneously, this document collects everything that has been entered by as many as 12 groups of students. All votes are tallied and percentages are displayed on a bar graph showing each option both before and after discussion. There is a place for teachers to also enter comparative results, for example, the national 
percentage that got this AP Physics B question right in 1984. Pie graphs display student opinions about the question, where the lighter the graph the more favorable the attitudes toward the question. Also of value is a display of each justification every group made supporting why they picked the answer they picked and an indication of how the majority of each group voted. In order to make the printout a stand-alone document, the original question is included.

A tab on the Report.xls document gives a printout of the summary page. ${ }^{7}$ Here, teachers can check radio buttons for the correct answers. When this is done, the number and percentage of students with the correct response for both pre- and post-discussion are pulled from the imported data and displayed while the maximum gain realized ${ }^{8}$ is calculated instantaneously. Conditional formatting highlights the gain as high (blue), medium (green), low (black), and negative (red). This gain is also displayed on a scatter-plot graph of (pre-) versus (post-minus pre-). Another option on this summary page is to use check boxes to break the 15 questions down into as many as eight changeable categories and display the average of all questions that fall into those categories on a bar graph. Another bar graph allows the teacher to monitor the success of individual groups.

\section{Support}

Though RFAS may be a unique use of spreadsheets, the methods of instruction and assessment have been at the forefront of current educational research. Two sources in particular, Peer Instruction ${ }^{9}$ and Assess-To-Learn, ${ }^{10}$ had a tremendous influence on the development of RFAS. Using these established programs as a framework, along with the research on which they are based, there were initially three goals for RFAS. The spreadsheets were to: serve the reflective practitioner, foster learning through formative assessment, and allow the development of understanding through social interaction. A fourth goal was added later that would allow students to exercise those skills necessary to do scientific inquiry.

\section{The Reflective Practitioner - RFAS allows} teachers to easily document and analyze student responses to a question and springboard them into a position where they can begin the reflection process instantaneously. It is the quick feedback that enhances reflection in two ways. One is through "reflectionon-action," as Schön ${ }^{11}$ would say, where the teacher uses a copy of the report to identify remaining misconceptions, re-plan the next lesson, re-write the next summative test, and/or share surprises with colleagues. Surveys such as the Force Concept Inventory $(\mathrm{FCI})^{12}$ and the Mechanics Baseline Test $(\mathrm{MBT})^{13}$ were designed for this type of reflection. Not only can such survey questions easily be placed within RFAS, but also RFAS can play a role in making the questions better. Schön's other type of reflection is "reflection-in-action." This method is commonly found where a teacher is skilled at questioning and can convincingly play the devil's advocate to continually challenge thought. With RFAS, teachers can be found among their students engaged in rich conversation while working from the RFAS report displayed through a digital projector or on a wireless laptop/tablet carried from group to group.

Formative Assessment - Currently there is a lot of focus on testing, including end-of-unit tests, endof-course exams, state tests, or standardized tests. For many these summative forms of measuring learning have become the sole method of assessment. One consequence is that formative assessment has been degraded down to the nonchalant "Are there any questions?" Sadly, some teachers cannot even recognize alternate forms of formative assessment when they see them. Take these spreadsheets for example. Some may say, "What's preventing a student from voting for the same distracter that the smart kid in the group voted for?" This is a good question and makes sense when these students are struggling to pick the right answer. In that case, questions used in the spreadsheet truly lack validity. However, when using formative assessment questions correctly, the student's intrinsic motivation to know the truth will override the extrinsic motivation to get it right. In this environment they challenge each other with "why do you think that is the correct answer?" It is important to remember that indoctrination is not the goal and that students must eventually be allowed to become self-learners. RFAS sets up a good environment to practice.

In the current high-stakes testing environment, 
educational research still condones the use of formative assessment. The NSTS Teaching Standard C, ${ }^{14}$ for example, supports the type of formative assessment that is capable through RFAS. A popular book that culminates a great deal of educational research and stresses the importance of formative assessment is called Assessment for Learning: Putting it into Practice. ${ }^{15}$ In it, Black et al. identify four things that have consistently shown to have a positive impact on education, all of which can be touched upon using RFAS. These include: giving students sufficient time to think about a question, providing students with feedback that they can use to extend learning, allowing students to engage in peer and self assessment, and making formative use of summative tests.

\section{Social Interaction - In his book Teaching Physics} with the Physics Suite, Edward Redish states, "For most individuals, learning is most effectively carried out via social interactions." 16 This is how an observation tool turns out to be an effective teaching tool. It stimulates dialogue and as the authors of the Reformed Teacher Observation Protocol (RTOP) ${ }^{17}$ observed, "Student talk is far more important than teacher talk." The RTOP is the result of research showing social interaction is a common thread between all current successful physics education programs. When students within a group are split on a RFAS question and there is only enough space for one justification per option, one of two things will happen: either the student must convince his or her peers to change their minds or get peers to clearly explain their reasons. Ultimately, one student teaches another, and the dialogue that occurs tends to be rich, reflective, and helpful in encouraging students to become independent learners.

Scientific Inquiry - In the student-centered environment established through RFAS, the teacher is most effective as a resource that stimulates divergent modes of thought without giving away answers. Originally, when RFAS used only traditional multiple-choice questions, students immediately saw the value in their discussions and the feedback given to the teachers but felt uncomfortable and somewhat frustrated in not being told the "right answers." In response, it was almost natural to give students an option to experiment and test the questions soon after they are discussed.

Recognizing that scientific inquiry is a very broad topic and encompasses a wide range of methodologies, we should note the type of inquiry performed with RFAS is "structured inquiry," which according to Wenning ${ }^{18}$ is an "activity focused on verifying information previously communicated in class." The idea is to give students an opportunity to explore ideas that lend support to one of the multiple-choice options. For example, suppose students are split on the question in Fig. 1. By allowing students to gather a mass, some string, and some spring scales, the student's intrinsic curiosity will stimulate the higher-order thinking skills necessary for good inquiry. Like Workshop Physics ${ }^{19}$ and Interactive Lecture Demonstrations, ${ }^{20}$ two programs that have successfully combined physics educational research and scientific inquiry, RFAS encourages students to make predictions about physical events, discuss their predictions, and then verify their predictions with real world interactions. Again, knowing the correct answer is not nearly as important as students communicating a justification for why it is the correct answer and why the distracters are either incomplete or inaccurate. In this regard, RFAS reflects the process of real science where the goal is not to provide proof, but to lend support by disproving.

\section{Conclusion}

Reflective formative assessment spreadsheets can provide teachers of any subject with a valuable tool. It has the ability of adding a special dimension to a great many educational programs without altering the objectives of those programs.

Though it does not look like a typical spreadsheet, it is important to remember that RFAS has all of the changeability of an Excel document and all of the tools that come with any Microsoft Office program. The website at http://www.k12.de.us/concord/ physics/, under Resources $->$ For Teachers $\rightarrow$ RFAS, provides a zipped file with prepared RFAS spreadsheets containing sample questions that highlight various ways that Excel can be utilized to work with and enhance other forms of computer-based technology and accommodate special learning needs.

At this site I've also posted physics examples, templates, instructions, and a multimedia presentation 
that gives a visual overview.

\section{Acknowledgment}

The development of RFAS probably would not have happened if not for the inspiration of Dylan Wiliam, coauthor of Assessment for Learning: Putting It into Practice.

\section{References}

1. Annie B. Elliott, Stephen D. Murray, and Richard A. Ward, "Spreadsheet-based exercises for introductory laboratories," Phys. Teach. 41, 18-19 (Jan. 2003).

2. David Byrd and Gary White, "Alternative theoretical method for motion of a sand-filled funnel experiment," Phys. Teach. 39, 464-465 (Nov. 2001).

3. Gordon J. Aubrecht II, T. Kenneth Bolland, and Michael G. Ziegler, "Animations in spreadsheets," Phys. Teach. 37, 540-541 (Dec. 1999).

4. R.J. Beichner, "Visualizing potential surfaces with a spreadsheet," Phys. Teach. 35, 95-97 (Feb. 1997).

5. AP physics B: Free-response Scoring Guide with Multiplechoice Section (College Entrance Examination Board, New York, 1984).

6. See RFASFig2.doc at http://ftp.aip.org/cgi-bin/ epaps?ID=E-PHTEAH-45-012701. For more information on EPAPS, see http://www.aip.org/pubservs/epaps. html.

7. See RFASFig3.doc at http://ftp.aip.org/cgi-bin/ epaps?ID=E-PHTEAH-45-012701. For more information on EPAPS, see http://www.aip.org/pubservs/epaps. html.

8. Richard Hake, "Interactive-engagement vs. traditional methods: A six-thousand-student survey of mechanics test data for introductory physics courses," Am. J. Phys. 66, 64-74 (Jan. 1998).

9. E. Mazur, Peer Instruction: A Users Manual (Prentice Hall, Upper Saddle River, NJ, 1997).

10. Robert J. Dufresne, William J. Gerace, William J. Leonard, and Ian D. Beatty, Assessing-To-Learn (A2L): Reflective Formative Assessment Using a Classroom Communication System, Pathways to Change: An International Conference on Transforming Math and Science Education in the K16 Continuum, Crystal City, Arlington, VA, April 21, 2002.

11. D. Schön, Educating the Reflective Practitioner (Josey Bass, San Francisco, 1987).

12. D. Hestenes, M.Wells, and G. Swackhamer, "Force concept inventory," Phys. Teach. 30, 141--158 (March 1992).
13. D. Hestenes and M. Wells, "A mechanics baseline test," Phys. Teach. 30, 159-166 (March 1992).

14. Scope, Sequence, and Coordination of Secondary School Science: A High School Framework for National Science Education Standards, Vol. III ( NSTA, Arlington, VA, 1995).

15. P. Black, C. Harrison, C. Lee, B.Marshal, and D.Wiliam, Assessment for Learning: Putting It into Practice (Open University Press, New York, 2003).

16. Edward Redish, Teaching Physics with Physics Suite (Wiley, New York, 2003), p. 39.

17. D. MacIsaac and K. Falconer, "Reforming physics instruction via RTOP,” Phys. Teach. 40, 479-485 (Nov. 2002).

18. C. Wenning, "Levels of inquiry: Hierarchies of pedagogical practices and inquiry processes," J. Phys. Teach. Educ. Online 2(3), 3-11 (Feb. 2005); http://www.phy. ilstu.edu/jpteo/issues/jpteo2(3)feb05.pdf.

19. P. Laws, Workshop Physics: Activity Guide (Wiley, New York, 1999).

20. D.R. Sokoloff and R.K. Thornton, Interactive Lecture Demonstrations (Wiley, New York, 2001).

PACS codes: 01.40.-d, 01.50.ht, 01.40.gb

Jud Wagner received a B.S. degree in physics from
Elizabeth College and an M.Ed. from Wilmington College.
He is a National Board Certified teacher and has taught
physics at Concord High School since 1996.
Concord High School, Wilmington, DE 19810; judson.
wagner@bsd.k12.de.us

